Macedonian Pharmaceutical Bulletin, 66 (Suppl 1) 5 - 6 (2020)

Online ISSN 1857 - 8969

UDC: 615.213 .033

DOI: 10.33320/maced.pharm.bull.2020.66.03.002

Short communication

\title{
Therapeutic drug monitoring of valproic acid through plasma concentration
}

\author{
Verica Jakjimoska $^{1}$, Biljana Gjorgjeska $^{2}$ \\ ${ }^{1}$ General City Hospital " 8 th September”, Central Biochemical Laboratory, Pariska bb, \\ 1000 Skopje, N. Macedonia \\ ${ }^{2}$ Faculty of Medical Science, University “Goce Delcev” Stip, Krste Misirkov 10A, 2000 Stip, N. Macedonia
}

\section{Introduction}

Therapeutic drug monitoring is the measurement of specific drug and/or their breakdown products (metabolites) at timed intervals to maintain a relatively constant concentration of the medication in the blood. Some of the monitored drugs tend to have a narrow "therapeutic index", which is a ratio between the toxic and therapeutic (effective) dose of medication.

Burtn et al. (2006) have shown that valproic acid is an 8-carbon 2-chain fatty acid that is metabolized by the liver and processed at a variable rate based on the patient's liver function and age, in addition to patient's other routine medications with which valproic acid may interact. At therapeutic concentrations, valproic acid mediates prolonged recovery of voltage-activated $\mathrm{Na}^{+}$channels, thereby inhibiting repetitive firing induced by depolarization of cortical and spinal cord neurons.

Unborn babies exposed to valproate are at very high risk of neurodevelopment disability and other birth defects and the need for effective contraception planning must also be emphasized, along with the requirement for specialist oversight to safely change their medication if planning a pregnancy according toMarshall and Bangert (2008).

The determination of an antiepileptic drug concentration is recommended as a baseline measurement after starting drug therapy, according to NICE Clinical Guideline 137 (2020), after a change in the drug dose regimen, after addition of a second drug that may interact with the antiepileptic drug, and after a change in the patient's liver, cardiac, or gastrointestinal function.According to NICE Clinical Guideline 38 (2020), measurement of an antiepileptic drug concentration is usually performed after 4 to 5 elimination half-lives of drug administration, that is, once a steady state concentration has been achieved.

\section{Materials and methods}

This is a retrospective study on 40 patients over the period from January the $9^{\text {th }}$ to March the $11^{\text {th }}$ 2020. All serum samples were selected from specimens submitted to the laboratory for routine antiepileptic drug testing for valproic acid. The analyses were performed using an automated analyzer Immulite 2000, competitive immunoassay methods for the quantitative measurement of valproic acid. The Immulite 2000 is an automated random access analyzer that uses chemiluminescence technology.

The therapeutic range for valproic acid is 50-100 $\mathrm{mcg} / \mathrm{mL}$, sub-normal level is $<50 \mathrm{mcg} / \mathrm{mL}$, and the toxic level is $>100 \mathrm{mcg} / \mathrm{mL}$.

\footnotetext{
*verica_flash@yahoo.com
} 


\section{Result and discussion}

In this study were analyzed 40 patients coming from the department of neurology and psychiatry, patients with epilepsy or with bipolar mood disorders and other neuralgia. Males represented $37.5 \%$ of the total number of patients, and females $62.5 \%$, which is $25 \%$ more than males, showing that females are more vulnerable. Standard deviation for patient's age within this population with $95 \%$ confidence interval was $45.9 \pm 5.4$ years. Female only, has shown lower age standard deviation with $95 \%$ confidence interval of $32.5 \pm 2.5$ years. Approximately $42.5 \%$ of the population were with normal serum level of valproic acid (50-100 $\mathrm{mcg} / \mathrm{mL}$ ), and $57.5 \%$ were with sub-normal serum level of valproic acid $(<50 \mathrm{mcg} / \mathrm{mL})$, and none with toxic level of valproic acid $(>100 \mathrm{mcg} / \mathrm{mL})$ in serum samples. Within $95 \%$ confidence interval, serum levels were measured to be $46.4 \pm 7.5( \pm 16 \%)$ $\mathrm{mcg} / \mathrm{mL}$. Mean of inter-individual variability in valproic acid serum concentrations were $38.9 \% \mathrm{CV}$ for dose of $400 \mathrm{mg} /$ day, $45.8 \% \mathrm{CV}$ for dose of 600 $\mathrm{mg} /$ day, and $14.25 \% \mathrm{CV}$ for dose of $800 \mathrm{mg} /$ day.

As demonstrated (Warner et al., 1998), many of the drugs that require therapeutic monitoring are taken for a lifetime. They must be maintained at steady concentrations year after year while the person ages and goes through life events that may alter that individual's therapeutic level, including pregnancies, temporary illnesses, infections, emotional and physical stresses, accidents, and surgeries.

Tests that measure drug concentration in serum are used to monitor blood levels of drugs that have a narrow range in which the drug is effective, but not toxic. It was shown that no toxicity was found and therapeutic response was satisfying within $42.5 \%$ of the patients. There is significant number of patients $(57.5 \%)$ with sub-normal serum level of valproic acid, partially because this low level has satisfactory therapeutic response, but there is still chance for non-compliance. In addition, Shaikh (2018) demonstrated that some drugs require monitoring because the dosage of drug given does not correlate well with the concentration of drug that may reach the blood. Sometimes, the way that a drug is absorbed and metabolized can vary from person to person, or the physical or health status of a person can affect the drug level in the blood. Through years of testing, the optimum therapeutic ranges for drugs have been determined. In these ranges, most people will be effectively treated without excessive side effects or symptoms of toxicity.

\section{Conclusion}

Patients treated with valproic acid are most likely woman at the age of 30-35 years, still in reproductive period and have childbearing potential. This fact requires protection for girls and young women, and using valproic acid only when other medications have not been tolerated or have been found to be ineffective. It is vital where valproate is prescribed to girls and women of childbearing potential that they are made aware of the risks of taking the medication in pregnancy. Sub-normal level of valproic acid in serum is partially because this low level has satisfactory therapeutic response but there is still chance for non-compliance.

\section{References}

Burtn, M.E., Shaw, L.M., Schentag, J.J., Evans, W.E., 2006. Applied Pharmacokinetics \& Pharmacodynamics, fourth ed. Baltimore, Philadelphia: Lippincott Williams \& Wilkins. ISBN 978-0-7817-4431-7.

Marshall, W.J., Bangert, S.K. 2008. Clinical Chemistry, sixth ed. Edinburgh, London: Mosby Elsevier. ISBN 978-0-7234-3455-9.

NICE Clinical Guideline 137: The epilepsies: diagnosis and management of the epilepsies in adults in primary and secondary care (Published: Jan 2012, Last updated: Feb 2020).

NICE Clinical Guideline 38: The management of bipolar disorder in adults, children and adolescents in primary and secondary care (Published: Sept 2014, Last updated Feb 2020).

Shaikh, A.S., Liu, H., Li, Y., Cao, L., Guo, R. 2018. Therapeutic drug monitoring of valproic acid. Pak. J. Pharm. Sci. 31(4(Special)), 1773-1776.

Warner, A., Privitera, M., Bates, D., 1998. Standards of laboratory practice: antiepileptic drug monitoring. National Academy of Clinical Biochemistry. Clinical Chemistry 44, 1085-1095.

Maced. Pharm. Bull. 66 (Suppl 1) 5 - 6 (2020) 